\title{
Improved Antitumor Outcomes for Colon Cancer Using Nanomicelles Loaded with the Novel Antitumor Agent LA67
}

This article was published in the following Dove Press journal: International Journal of Nanomedicine

\author{
Minhu Cui ${ }^{1,2}$ \\ Mingji Jin ${ }^{2}$ \\ Mingfeng $\operatorname{Han} \mathbb{1}^{2}$ \\ Yingda Zang ${ }^{2}$ \\ Chuangjun $\mathrm{Li}^{2}$ \\ Dongming Zhang (D) $^{2}$ \\ Wei Huang ${ }^{2}$ \\ Zhonggao Gao (iD) ${ }^{2}$ \\ Xuezhe Yin $^{3}$ \\ 'Department of Gastroenterology, \\ Yanbian University Hospital, Yanji \\ 133000, Jilin, People's Republic of China; \\ ${ }^{2}$ State Key Laboratory of Bioactive \\ Substance and Function of Natural \\ Medicines, Institute of Materia Medica, \\ Chinese Academy of Medical Sciences \\ and Peking Union Medical College, Beijing \\ 100050, People's Republic of China; \\ ${ }^{3}$ Department of Respiratory Medicine, \\ Yanbian University Hospital, Yanji \\ 133000, Jilin, People's Republic of China
}

Correspondence: Zhonggao Gao State Key Laboratory of Bioactive Substance and Function of Natural Medicines, Institute of Materia Medica, Chinese Academy of Medical Sciences and Peking Union Medical College, Beijing I00050, People's Republic of China Tel/Fax +86 10-63028096

Email zggao@imm.ac.cn

Xuezhe Yin

Department of Respiratory Medicine, Yanbian University Hospital, Yanji 133000 , jilin, People's Republic of China

Tel/Fax +86-433-28I7019

Email yinxz|234@I63.com
Background: LA67 is a derivative of triptolide that exhibits strong antitumor activity. This derivative has a better safety profile than triptolide, but is limited by poor aqueous solubility. Aim and Methods: To improve solubility and further increase therapeutic efficacy, we prepared LA67-loaded polymeric micelles (LA67-PMs) using a film hydration method. The physicochemical properties of LA67-PMs were investigated, and the antitumor activity of this formulation against Colon26 (C26) cancer cell line was evaluated in vitro and in vivo with LA67 as a control.

Results: Polymeric micelles containing LA67 had a particle size of $17.88 \mathrm{~nm}$ and a drug entrapment efficiency of $94.84 \%$. This formulation dispersed completely in aqueous solution and exhibited slow, sustained release of LA67. Cellular uptake assay showed that LA67-PMs delivered LA67 to cancer cells with greater efficiency than free LA67, which resulted in increased LA67 accumulation in cancer cells. Cell counting kit 8 (CCK-8) assay showed that blank polymeric micelles (PMs) exhibited low toxicity and LA67-PMs exerted pronounced antiproliferation effects against C26 cells. Furthermore, LA67-PMs induced apoptosis and repressed migration more effectively than free LA67. In vivo evaluation of antitumor activity showed that LA67-PMs inhibited tumor growth and distant organ metastasis to a greater extent than LA67, which resulted in improved survival rate. The potential mechanisms of these effects may have been induction of apoptosis, inhibition of cell proliferation, and neovascularization.

Conclusion: Our study showed that LA67-PMs may be a promising formulation for treatment of colon cancer.

Keywords: triptolide derivatives, polymeric micelles, small size, tumor therapy

\section{Introduction}

Colorectal cancer (CRC) is the third most common malignant tumor and the fourth most common cause of cancer-related death. More than one million new cases of CRC are diagnosed each year, and about 835,000 people died from CRC in 2015 worldwide. $^{1,2}$ Surgical resection is the most common treatment for early stage CRC, and chemotherapy and biotherapy are the main treatments for patients with advanced and recurrent $\mathrm{CRC}$. $^{3}$ Nearly half of patients with CRC have organ metastasis. Over the past 40 years, use of 5FU as a chemotherapeutic agent has significantly improved the prognosis of patients with advanced $\mathrm{CRC}{ }^{4}$ but its efficacy has been limited by lack of chemotherapeutic selectivity, which results in toxicity and adverse drug reactions. ${ }^{5-7}$ Development of new drugs to treat CRC that causes less side effects and exert improved therapeutic effects is critical. 
Triptolide (TP), a diterpenoid triepoxide, is derived from the herb Tripterygium wilfordii Hook F. ${ }^{8}$ Previous studies have shown that triptolide is a broad-spectrum tumor inhibitor that can inhibit about 60 cancer cell lines. ${ }^{9-18}$ Triptolide exhibits stronger antitumor activity than traditional antineoplastic drugs such as doxorubicin, mitomycin, cisplatin, and paclitaxel. ${ }^{16}$ The antitumor mechanisms of triptolide have not been characterized, but they may be related to induction of apoptosis, inhibition of cell proliferation, and neovascularization. Despite exhibiting efficacy against various diseases, the clinical application of triptolide has been limited due to poor aqueous solubility, short half-life in the circulation, and serious side effects. Many triptolide derivatives have been developed, ${ }^{19-22}$ including LA67 (Figure 1), ${ }^{23}$ which was prepared from a modified triptolide synthesis procedure at our institute by Prof Dongming Zhang. Previous studies have shown that LA67 inhibited growth of melanoma in vitro and in vivo. Although LA67 is less toxic than triptolide, it is poorly water soluble, and is difficult to prepare for intravenous injection. Therefore, development of a drug delivery system for intravenous infusion of LA67 is important.

Controlled release and targeted nano-drug delivery systems have attracted extensive attention in the field of drug delivery. ${ }^{24-26}$ Among novel delivery systems, polymeric micelles have been developed as ideal carriers for delivery of antitumor drugs in the past two decades. ${ }^{27-29}$ Polymeric micelles are thermodynamically stable colloidal solutions formed by self-assembly of amphiphilic block copolymers in water. In addition to being used to aid drug solubilization, polymeric micelles can also improve drug stability, control drug release, optimize drug distribution, prolonged blood circulation time, and passively target cancer cells via the EPR effect, thus reducing side effects and improving therapeutic effects. ${ }^{30-34}$ Recently, there have been many nano-sized macromolecular anticancer drugs developed based on the EPR effect, such as Genexol-PM ${ }^{\circledR}$, which came to market in

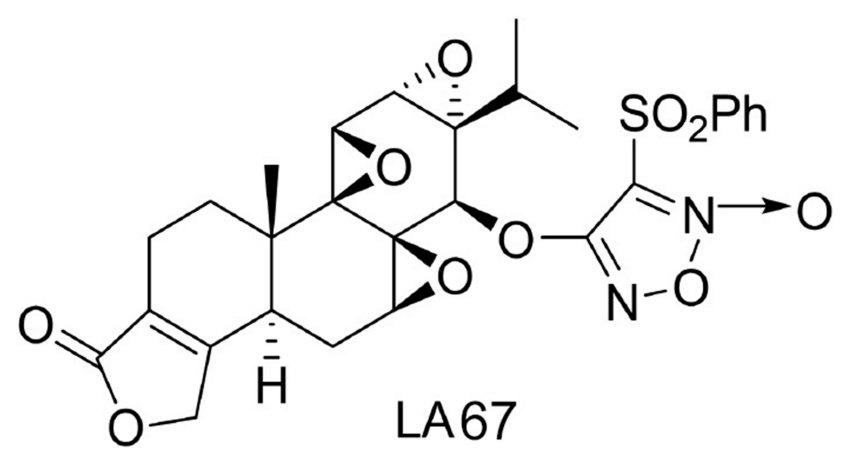

Figure I Chemical structure of LA67.
2006 and is infused intravenously in clinical use. Genexol$\mathrm{PM}^{\circledR}$ is a novel polymeric micelle formulated paclitaxel using biodegradable block copolymer. In vivo, Genexol-PM ${ }^{\circledR}$ showed enhanced antitumor activity and much higher concentration in the tumor site, than did paclitaxel. ${ }^{35,36}$ After intravenous injection of nanomicelles loaded with antitumor agent, tumors exhibit the EPR effect, and drugs leak out from tumor vessels and accumulated in tumor sites. This tumorselective delivery consequently led to a markedly regressed tumor, without serious adverse side effects. Triptolide-loaded polymeric micelles are promising nano-scale formulations because of small particle size, good targeting ability, and improved solubility. ${ }^{27,28,37,38}$ In our previous study, we prepared docetaxel-loaded and Lx2-32c-loaded polymeric micelles. ${ }^{39,40}$ Our results showed that polymeric micelles were stable and effective vectors for antitumor drugs.

In the present study, LA67-PMs were prepared using $\mathrm{mPEG}_{2000}-\mathrm{PLA}_{1300}$ copolymer to take advantage of the superior antitumor effects of LA67. Stable LA67-PMs were developed using a film hydration method and the physicochemical properties of this formulation were evaluated. In addition, intracellular uptake and cytotoxicity of these polymeric micelles were investigated. The effects of LA67-PMs on C26 cell apoptosis, proliferation, and migration were evaluated in vitro. Moreover, the inhibitory effects on tumor growth and organ metastasis, and the potential antitumor mechanisms of LA67-PMs were investigated in vivo. Finally, we investigated the impact of LA67-PMs on the survival time of mice.

\section{Materials and Methods}

\section{Materials}

Double-block copolymer $\mathrm{mPEG}_{2000}-\mathrm{PLA}_{1300}$ was purchased from Shanxi Kangbao Biotechnology Co., Ltd. (Shanxi, China). LA-67 $\left(\mathrm{C}_{28} \mathrm{H}_{28} \mathrm{O}_{10} \mathrm{~N}_{2} \mathrm{~S}\right.$, MW 584.1465, purity 99.9\%) was supplied by Prof Dongming Zhang from the State Key Laboratory of Bioactive Substance and Function of Natural Medicines, Institute of Materia Medica, Chinese Academy of Medical Sciences (CAMS) and Peking Union Medical College (PUMC). Annexin V-fluorescein isothiocyanate (FITC) apoptosis detection kit was purchased from Neo Bioscience (Shenzhen, China). Coumarin-6 (C6) was obtained from Sigma-Aldrich, Co. Cell Counting Kit-8 (CCK-8) was purchased from Dojindo Laboratories (Kumamoto, Japan).

\section{Preparation of LA67-PMs}

Polymeric micelles containing LA67 were prepared using a film hydration method. ${ }^{40}$ Briefly, $3 \mathrm{mg}$ of LA67 and 150 
$\mathrm{mg}$ of $\mathrm{mPEG}_{2000}-\mathrm{PLA}_{1300}$ were dissolved in $3 \mathrm{~mL}$ of acetonitrile. Then, acetonitrile was removed by rotary evaporation in a water bath $\left(50{ }^{\circ} \mathrm{C}\right.$ for $\left.40 \mathrm{~min}\right)$. Then, $10 \mathrm{~mL}$ of distilled water was added to hydrate the film, and LA67-PMs were formed by self-assembly after $30 \mathrm{~min}$. Blank PMs were prepared in the same manner described in the absence of LA67.

\section{Particle Size, Zeta Potential and Morphology of LA67-PMs}

Electrophoretic light scattering and dynamic light scattering were used to determine the particle size and zeta potential of LA67-PMs using a Zetasizer Nano ZS90 (Malvern, UK). The morphology of LA67-PMs was visualized using a transmission electron microscopy (TEM) (Hitachi H-7650, Japan).

\section{Reconstitution Stability of LA67-PMs}

Fifty milligrams of LA67-PMs lyophilized powder was dissolved in $5 \%$ glucose solution to obtain a $0.3 \mathrm{mg} / \mathrm{mL}$ LA67-PMs solution. The solution was held at room temperature $\left(25^{\circ} \mathrm{C}\right)$ for 0,1 , and 7 days, and reconstitution stability of LA67-PMs was determined by measuring particle size and PDI values.

\section{Loading Capacity and Encapsulation Efficiency of LA67-PMs}

A high-performance liquid chromatography (HPLC) system was used to determine the loading capacity (LC) and drug encapsulation efficiency (EE) of LA67-PMs.The mobile phase consisted of methanol:water (70:30), the injection volume was $10 \mu \mathrm{L}$, the column temperature was set at $30{ }^{\circ} \mathrm{C}$, and the flow rate was $1 \mathrm{~mL} / \mathrm{min}$. The ultraviolet absorbance was determined at $254 \mathrm{~nm}$. Ten milligrams of LA67 powder was accurately weighed and dissolved in $10 \mathrm{~mL}$ of acetonitrile to obtain an LA67 stock solution $(1 \mathrm{mg} / \mathrm{mL})$. A series of solutions prepared at $5,10,25,50,100$, and $150 \mu \mathrm{g} / \mathrm{mL}$ were obtained by diluting the stock solution with mobile phase, and analyzed using HPLC to generate a standard curve.

Thirty milligrams of LA67-PMs lyophilized powder was dissolved in distilled water to obtain an LA67-PMs solution. Large particles were removed using a $0.22-\mu \mathrm{m}$ membrane. Filtered and unfiltered LA67-PMs solutions $(300 \mu \mathrm{L})$ were diluted with acetonitrile. Following ultrasonication and centrifugation, the supernatants were collected to determine the LA67 concentration. The LC and EE of LA67-PMs were calculated as follows:

$$
\begin{gathered}
\mathrm{LC} \%=\frac{\text { weight of encapsulated drug }}{\text { weight of total drug and vector }} \times 100 \% \\
\mathrm{EE} \%=\frac{\text { weight of encapsulated drug }}{\text { weight of total drug }} \times 100 \%
\end{gathered}
$$

\section{In vitro Release}

Fifty milligrams of LA67-PMs lyophilized powder was dissolved in 5\% glucose solution to obtain an LA67-PMs solution $(1 \mathrm{mg} / \mathrm{mL})$. One milliliter of LA67-PMs solution was transferred to a dialysis bag (MW cutoff: $10 \mathrm{kDa}$ ). The dialysis bag was placed in a triangular flask with 10

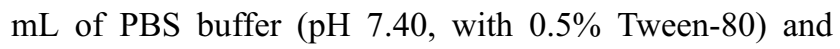
shaken in a thermostatic oscillator $\left(100 \mathrm{rpm}\right.$ at $\left.37^{\circ} \mathrm{C}\right)$. Then, $0.5 \mathrm{~mL}$ of release medium was removed at the designated time points, and $0.5 \mathrm{~mL}$ fresh medium was added back to the release media. After centrifugation (10,000 rpm, $10 \mathrm{~min})$, the LA67 concentration in the samples was determined. A release curve was plotted using the amount of released LA67.

\section{Cell Line and Animals}

Mouse colon cancer cells (C26) were purchased from the Cell Culture Center of Institute of Basic Medical Sciences in CAMS. Male BALB/c mice (5 weeks old, 18-22 g) were purchased from Vital River Laboratory Animal Technology Co., Ltd. (Beijing, China). All animal experiments were conducted in accordance with the standard protocol approved by the Institute of Materia Medica in CAMS and PUMC.

\section{Cellular Uptake Assay}

Coumarin-6 was encapsulated into polymeric micelles for detection of intracellular uptake of PMs into C26 cells. Mouse C26 cells were cultured in 12 -well plates $\left(10 \times 10^{4}\right.$ cells/well) on coverslips for $24 \mathrm{~h}$. Then, the culture medium was carefully removed, and fresh culture medium containing C6 or C6-PMs was added, and the cells were incubated for 5, 15, 30, and $60 \mathrm{~min}$. After washing with PBS buffer, the cells were fixed with $4 \%$ paraformaldehyde solution. The cells on coverslips were visualized and photographed using a confocal laser scanning microscope (TCS-SP2, Germany).

In addition, C26 cells were cultured in 6-well plates $\left(15 \times 10^{4}\right.$ cells/well $)$ for $24 \mathrm{~h}$. The culture medium was 
carefully removed, and fresh culture medium containing C6-PMs or C6 was added, and the cells were incubated for 15 and $60 \mathrm{~min}$. After washing with PBS buffer, the cells were collected for analysis. The fluorescence intensity of cells in each group was measured using flow cytometry (BD, USA).

\section{Cell Viability Assay}

The cytotoxicity of blank PMs and the anti-proliferation effects of LA67-PMs on C26 cells were evaluated using CCK-8 assay. C26 cells were cultured in 96-well plates $\left(6 \times 10^{3}\right.$ cells/well). After $24 \mathrm{~h}$, the culture medium was carefully removed, and fresh culture medium containing LA67, LA67-PMs, or blank PMs was added. After an additional 24, 48 , or $72 \mathrm{~h}$, cells in each well were treated with CCK-8 reagent according to the manufacturer's instructions. Optical density values were detected using a Synergy H1 Microplate Reader (BioTek, Winooski, VT, USA).

The following formula was used to calculate cell viability:

$$
\text { cell viability }(\%)=\frac{\mathrm{OD}_{\text {test }}-\mathrm{OD}_{\text {blank }}}{\mathrm{OD}_{\text {control }}-\mathrm{OD}_{\text {blank }}} \times 100 \%
$$

\section{Cell Apoptosis Assay}

Mouse C26 cells were cultured in 6 -well plates $\left(15 \times 10^{4}\right.$ cells/well) for $24 \mathrm{~h}$. Then, the culture medium was carefully removed, and fresh culture medium containing LA67, LA67-PMs, or blank PMs was added, and the cells were incubated for $48 \mathrm{~h}$. A control group was evaluated in parallel. After washing with PBS buffer, the cells were treated with Annexin V-FITC apoptosis detection kit following the manufacturer's instructions. The samples were analyzed immediately using a FACS Aria flow cytometer.

\section{Wound Healing Assay}

Mouse C26 cells were cultured in 12 -well plates $\left(10 \times 10^{4}\right.$ cells/well). After $24 \mathrm{~h}$, a wound field was made in the middle of each well with a $200-\mu \mathrm{L}$ plastic pipette tip, and debris was rinsed three times with PBS. Then, the culture medium was carefully removed, and fresh culture medium containing LA67 or LA67-PMs solution was added. A control group was evaluated in parallel. Scratch healing was observed using a light microscope (Olympus, Japan) at 0,24 , and $48 \mathrm{~h}$.

\section{Evaluation of Antitumor Effects of LA67- PMs in vivo}

The mice were subcutaneously injected in the right flank with $0.1 \mathrm{~mL}$ suspensions of $\mathrm{C} 26$ cancer cells $\left(1 \times 10^{7}\right.$ cells/ $\mathrm{mL}$ ). The mice were randomly divided into four groups $(\mathrm{n}=6)$, including saline, blank PMs, LA67, and LA67-PMs groups, when the volume of tumors reached $50-100 \mathrm{~mm}^{3}$. Each group was administered a $0.3 \mathrm{mg} / \mathrm{kg}$ dose (LA67 content $0.3 \mathrm{mg} / \mathrm{kg}$ ) via tail vein injection once per day for 2 weeks. Body weights and tumor volumes were measured every other day. Tumor volume $=\operatorname{width}^{2} \mathrm{x}$ length $/ 2$. All mice were sacrificed by cervical dislocation on the day after the last administration. The tumors and livers of all mice were harvested and stained with hematoxylin and eosin (H\&E). All tumors were weighed and compared quantitatively.

\section{TUNEL Assay}

Analysis using TUNEL staining was performed to determine the apoptosis-inducing properties of LA67-PMs and free LA67 in vivo. The tumor tissues were treated with $4 \%$ paraformaldehyde (1 day) and 70\% ethanol (1 night). Subsequently, TUNEL assay was performed using a TUNEL-POD kit following the manufacturer's instructions. Apoptosis in tumor tissues was determined using an optical microscope.

\section{CD3I Assay}

The anti-angiogenesis effect of LA67-PMs and free LA67 was determined in vivo using a neovascularization immunofluorescence assay. Tumor tissues were frozen and sectioned into $3-5 \mu \mathrm{m}$ slices, then analyzed using a CD31 kit according to the manufacturer's instructions. Microvessel densities were detected using a fluorescence microscopy.

\section{Ki-67 Assay}

To evaluate the anti-proliferative effects of LA67-PMs and free LA67 in vivo, levels of Ki-67 protein were measured using immunofluorescence. Fixed and frozen sections of tumor tissues were analyzed using a Ki-67 kit according to the manufacturer's instructions. Ki-67-positive cells were detected using a fluorescence microscopy.

\section{Survival Analysis}

Forty $\mathrm{C} 26$ tumor-bearing mice were randomly divided into four groups $(\mathrm{n}=10)$, including saline, blank PMs, LA67, and LA67-PMs groups. Each group was administrated a 
$0.3 \mathrm{mg} / \mathrm{kg}$ dose (LA67 content $0.3 \mathrm{mg} / \mathrm{kg}$ ) via tail vein injection once per day for 2 weeks. Survival was evaluated continuously for 58 days after C26 cancer cells were injected into the mice. A survival curve was plotted using GraphPad Prism software.

\section{Statistical Analysis}

Data are presented as the mean \pm SD. Differences between two groups were determined using Student's $t$-test: * $\mathrm{P}<0.05$; ** $\mathrm{P}<0.01 ; * * * \mathrm{P}<0.001$. SPSS Statistics 22 (IBM Corporation, Armonk, NY, USA) was used for data analysis.

\section{Results and Discussion}

\section{Synthesis and Characterization of LA67- PMs}

Polymeric micelles allow for a wide drug-loading range, stable structure, slow and sustained drug release, prolonged circulation time, and a low incidence of side effects. Polymeric micelles have become promising nanocarriers that allow for targeted delivery of various therapeutic agents, and improved solubility and bioavailability. ${ }^{41-44}$ Previous studies have shown that polymeric micelles are stable and effective vectors for delivery of triptolide to solid tumors. ${ }^{27,28}$ In our previous study, LA67, a derivative of triptolide, exhibited a better safety profile than triptolide, but was poorly water soluble, which made preparation of intravenous injections difficult. To improve the solubility and efficacy of LA67, we prepared LA67-PMs using a film hydration method. As shown in Figure $2 \mathrm{~A}, \mathrm{mPEG}_{2000}-\mathrm{PLA}_{1300}$ encapsulated hydrophobic LA67 to form a transparent and homogeneous LA67-PMs suspension, which indicated that LA67-PMs were completely dissolved in the aqueous solution.

Figure 2B shows a TEM image of LA67-PMs. The results showed that LA67-PMs were spherical or quasi-spherical in appearance and nearly uniform in size. The average particle size of LA67-PMs was $17.88 \pm 0.84 \mathrm{~nm}$, the PDI was $0.145 \pm 0.02$ (Figure 2C), and the zeta potential was $-1.72 \pm$ $0.36 \mathrm{mv}$ (Figure 2D). The results of particle size measured by Malvern particle size analyzer were basically consistent with those observed by TEM. Zeta potential has a significant influence on the stability of particles through electrostatic repulsion. A high surface charge contributes to the better stability of the micelles. However, LA67-PMs had a neutral charge, which indicated that they might be unstable in an aqueous medium. We, therefore, conducted the stability experiment and found that LA67-PMs solution was stable for 7 days (stored at $4^{\circ} \mathrm{C}$ ) (Figure $2 \mathrm{E}$ and $\mathrm{F}$ ). The reason for this may be that the high content of PEG on the surface of micelles provides a repulsive force to reduce the surface tension between particles, thus helping to maintain stability.45,46 To determine LA67 content, a quantitative HPLC method was developed. A calibration curve was generated from 5 to $150 \mu \mathrm{g} / \mathrm{mL}$, and analysis of LA67 was linear across this range. The standard curve equation was $\mathrm{A}=4.7775 \mathrm{C}+$ $8.4248\left(\mathrm{r}^{2}=0.9999, \mathrm{n}=6\right)$. We determined the EE and LC of LA67-PMs (94.84 $\pm 1.09 \%$ and $1.8 \pm 0.01 \%$, respectively). Our results showed that LA67-PMs had good physicochemical properties and were easy to prepare, which confirmed that the polymeric micelles were ideal carriers for LA67.

\section{In vitro Release}

Controlled drug release is the primary advantage of polymeric micelles because it can promote increased duration of drug circulation and reduce toxicity, which results in improved therapeutic efficacy and reduced side effects. ${ }^{47,48}$ The cumulative release behavior of LA67 from LA67-PMs was evaluated in vitro using a dialysis method. Furthermore, LA67 release from LA67-PMs was slow and sustained. Release was steady, and no burst release was observed (as shown in Figure 3). These results showed that LA67 encapsulated in PMs was released from LA67-PMs continuously and slowly, which suggested that these PMs were appropriate carriers for LA67. Furthermore, DDsolver software was used to fit the drug release curve. As shown in Table 1, the release behavior of LA67-PMs was most consistent with the Weibull-sustained release model, with an $\mathrm{r}^{2}$ value of 0.9959 .

\section{Cellular Uptake Assay}

Coumarin-6 was encapsulated into polymeric micelles for the detection of intracellular uptake of PMs into C26 cells. Coumarin-6 is a relatively stable fat-soluble fluorescent dye, which is often encapsulated in nano-drug delivery systems to study mechanisms of intracellular uptake and transport. $^{40,49}$ Coumarin-6-stained nuclei showed green fluorescence signals (Figure 4A). After incubation with C6-PMs for $5 \mathrm{~min}$, the green fluorescence signal was detected. With increased incubation time, green fluorescence increased. In contrast, signals were not detected in response to free $\mathrm{C} 6$ for $30 \mathrm{~min}$.

Intracellular uptake efficiency of C6-PMs was quantitatively assessed using flow cytometry. Similar results were observed when the fluorescence intensity induced by C6PMs was compared with that induced by free C6. As shown in Figure $4 \mathrm{~B}$ and $\mathrm{C}$, the fluorescence intensity significantly 
A

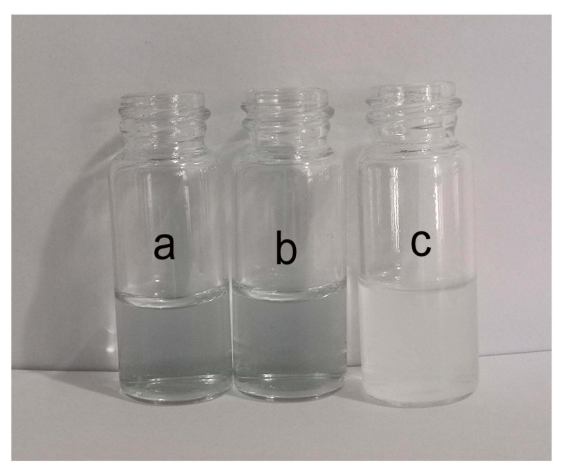

C

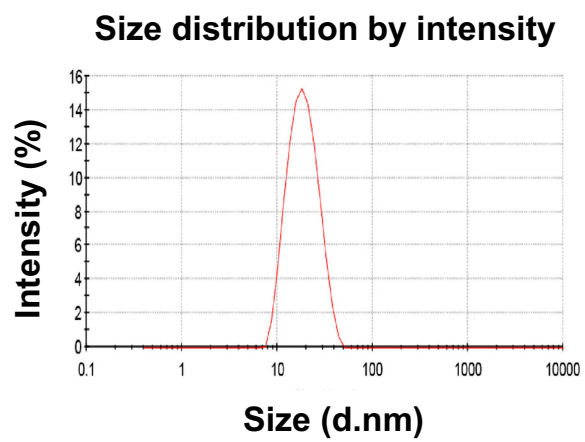

E

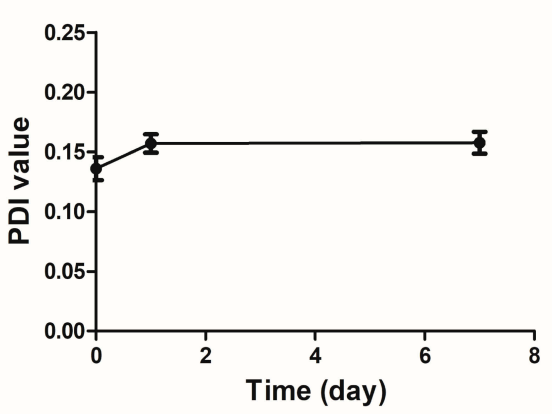

B

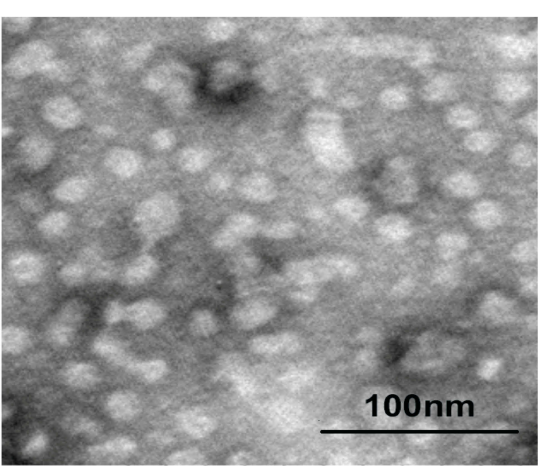

D

\section{Zeta potential distribution}

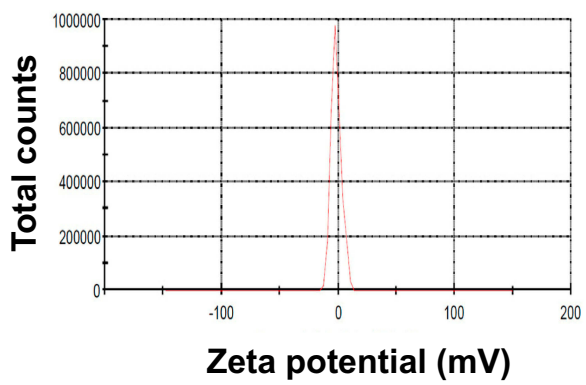

F

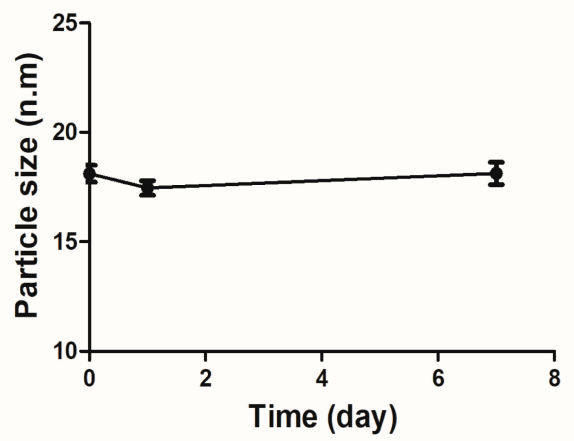

Figure 2 Characterization of LA67-PMs.

Notes: (A) a, PBS solution; b, LA67-PMs in PBS solution; c, free LA67 in PBS solution (from left to right). (B) TEM image (scale bar was I00 nm). (C) Size distribution. (D) Zeta potential. (E) PDI and (F) Particle size changes within 7 days after reconstitution with $5 \%$ glucose solution $(n=3$, mean \pm SD).

Abbreviations: LA67-PMs, LA67-loaded polymeric micelles; PBS, phosphate-buffered saline; PDI, polydispersity index; TEM, transmission electron microscopy.

increased in response to C6-loaded micelles at 15 and $60 \mathrm{~min}$ compared to that in response to free C6. $(P<0.01$ and $P<0.001)$. Polymeric micelles delivered LA67 to cancer cells more efficiently than free LA67, which indicated that incorporation of LA67 in polymeric micelles may improve efficiency and allow for expanded clinical application. This result was consistent with those of previous studies. ${ }^{40}$ These results may have been due to a number of factors. First, uptake of polymeric micelles might occur via endocytosis, while molecular diffusion may have been the main mechanism internalization of free drug into cancer cells. ${ }^{50}$ Second, the EPR effect may have promoted more effective transport of nanoparticles to cancer cells. ${ }^{51}$ Intracellular uptake of LA67 was significantly enhanced by polymeric micelle-mediated transport, which provided a strong basis for use of polymeric micelles for delivery of LA67. 


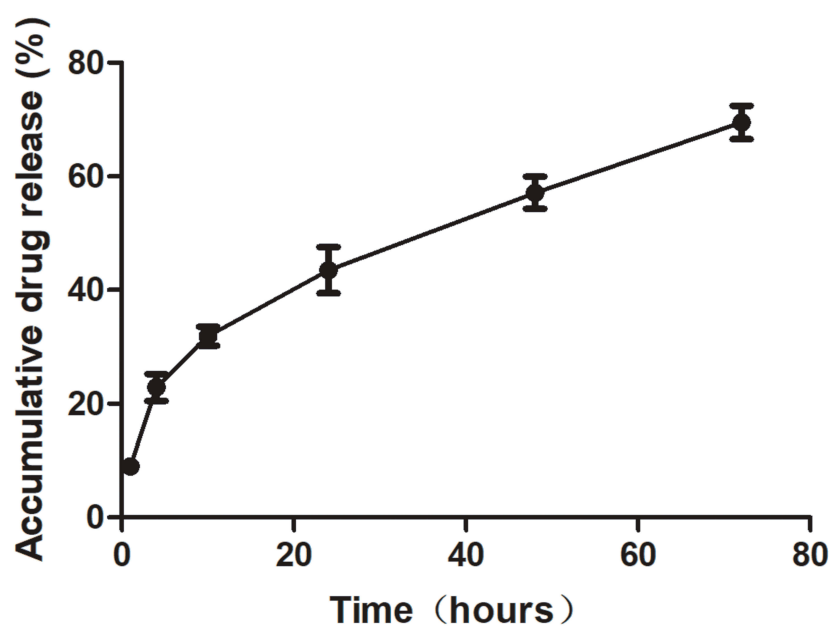

Figure 3 Release behavior of LA67-PMs in PBS $(\mathrm{pH} 7.4)$ at $37^{\circ} \mathrm{C}$. Abbreviations: LA67-PMs, LA67-loaded polymeric micelles; PBS, phosphate-buffered saline.

\section{Cytotoxicity of Blank PMs}

Vector safety is a critical factor for development of idea drug carriers. Therefore, we evaluated the cytotoxicity of blank polymeric micelles using the CCK-8 assay. As shown in Figure 5A, treatment with blank PMs at concentrations that would contain LA67 at concentrations ranging from 1 to 100 $\mathrm{ng} / \mathrm{mL}$ resulted in cell viability of $90 \%$, which indicated that the blank PMs exerted minimal cytotoxicity in C26 cells. These results showed that PMs were safe drug delivery carriers.

\section{Inhibitory Effects of LA67-PMs on C26 Cell Proliferation}

Cell counting kit 8 assay was used to evaluate the antiproliferative effects of free LA67 and LA67-PMs on C26 cells. As shown in Figure 5B, free LA67 and LA67-PMs effectively inhibited proliferation of $\mathrm{C} 26$ cells. Incubation

Table I Fit Result of LA67-PMs Release

\begin{tabular}{|c|c|c|c|}
\hline $\begin{array}{l}\text { Release } \\
\text { Model }\end{array}$ & Equation & Fit Result & $\begin{array}{l}\text { Fit } \\
\left(R^{2}\right)\end{array}$ \\
\hline Zero order & $\mathrm{F}=\mathrm{k} 0 * \mathrm{t}$ & $\mathrm{Q}=1.107 \mathrm{t}$ & 0.4660 \\
\hline First order & $\begin{array}{l}\mathrm{F}=100 *[1-\operatorname{Exp} \\
(-\mathrm{K} \mid * \mathrm{t})]\end{array}$ & $\mathrm{F}=100 *[1-\operatorname{Exp}(-0.020 * t)]$ & 0.7628 \\
\hline Higuchi & $\mathrm{F}=\mathrm{kH} \mathrm{H}^{*} \mathrm{t}^{\wedge} 0.5$ & $\mathrm{~F}=8.408 * \mathrm{t}^{\wedge} 0.5$ & 0.9650 \\
\hline $\begin{array}{l}\text { Peppas- } \\
\text { Sahlin }\end{array}$ & $\begin{array}{l}\mathrm{F}=\mathrm{k} \mid{ }^{*} \mathrm{t}^{\wedge} \mathrm{m}+\mathrm{k} 2{ }^{*} \mathrm{t}^{\wedge} \\
(2 * \mathrm{~m})\end{array}$ & $\begin{array}{l}\mathrm{F}=10.892 *{ }^{\wedge} 0.505-0.373 * \mathrm{t}^{\wedge} \\
(2 * 0.505)\end{array}$ & 0.9940 \\
\hline Weibull & $\begin{array}{l}\mathrm{F}=100 *\{1-\operatorname{Exp}[-((\mathrm{t}- \\
\left.\left.\left.\mathrm{Ti})^{\wedge} \beta\right) / \alpha\right]\right\}\end{array}$ & $\begin{array}{l}\mathrm{F}=100 *\{1-\operatorname{Exp}[-((\mathrm{t}-0.350) \\
\wedge 0.517 / 8.449]\}\end{array}$ & 0.9959 \\
\hline
\end{tabular}

Notes: In the table, the symbols * and ^ represent multiply and exponential power. Abbreviation: LA67-PMs, LA67-loaded polymeric micelles. of C26 cells with free LA67 or LA67-PMs at low concentrations $(1-10 \mathrm{ng} / \mathrm{mL})$ for $24 \mathrm{~h}$ did not result in reduced cell viability. Increased concentration and treatment duration resulted in strong inhibitory effects, as evidenced by decreased cell viability after 48 or $72 \mathrm{~h}$ of incubation. Furthermore, the inhibitory effects of LA67-PMs on C26 cell proliferation were more pronounced than those in response to free LA67.

\section{Influence of LA67-PMs on C26 Cell Apoptosis}

Annexin V-FITC/PI double-staining assay was used to evaluate apoptosis in response to LA67 and LA67-PMs. As shown in Figure 6, the proportions of apoptotic cells in the LA67-PMs, LA67, blank PMs, and control groups were $36.60 \pm 1.10 \%, 15.29 \pm 1.04 \%, 2.19 \pm 0.41 \%$, and $1.06 \pm$ $0.05 \%$, respectively. These results showed that LA67 and LA67-PMs induced late apoptosis of C26 cells, and the apoptosis rate in the LA67-PMs group was significantly higher than that in the LA67 group $(P<0.01)$. Moreover, the blank solution and blank PMs did not significantly induce apoptosis in $\mathrm{C} 26$ cells. These findings demonstrated that LA67-PMs induced apoptosis more effectively than free LA67, and blank PMs had little effect on cell apoptosis.

\section{Impact of LA67-PMs on Scratch Healing Ability}

To evaluate the impact of LA67-PMs on migration of C26 cells, wound healing assay was performed. As shown in Figure 7, incubation for $24 \mathrm{~h}$ with free LA67 and LA67PMs resulted in decreased numbers of cells, and increased intercellular space. In contrast, the scratches began to heal in the control group. After $48 \mathrm{~h}$ of incubation, the scratches had completely healed in the control group, but the scratches were still clearly visible in the administration group. The scratch width in the cells treated with LA67-PMs was wider than that in the cells treated with free LA67. These results suggested that LA67-PMs inhibited migration of C26 cells, which resulted in reduced scratch healing.

\section{In vivo Antitumor Effects of LA67-PMs}

In our study, $0.3 \mathrm{mg} / \mathrm{kg}$ of LA67 was determined to be a welltolerated dose. All groups were administrated a dose of 0.3 $\mathrm{mg} / \mathrm{kg}$ (LA67 content $0.3 \mathrm{mg} / \mathrm{kg}$ ) via tail vein injection once per day for 2 weeks. All mice survived the experiment. Figure $8 \mathrm{~A}$ and $\mathrm{D}$ show that the tumor volumes in the saline group and blank PMs group increased rapidly. In contrast, 


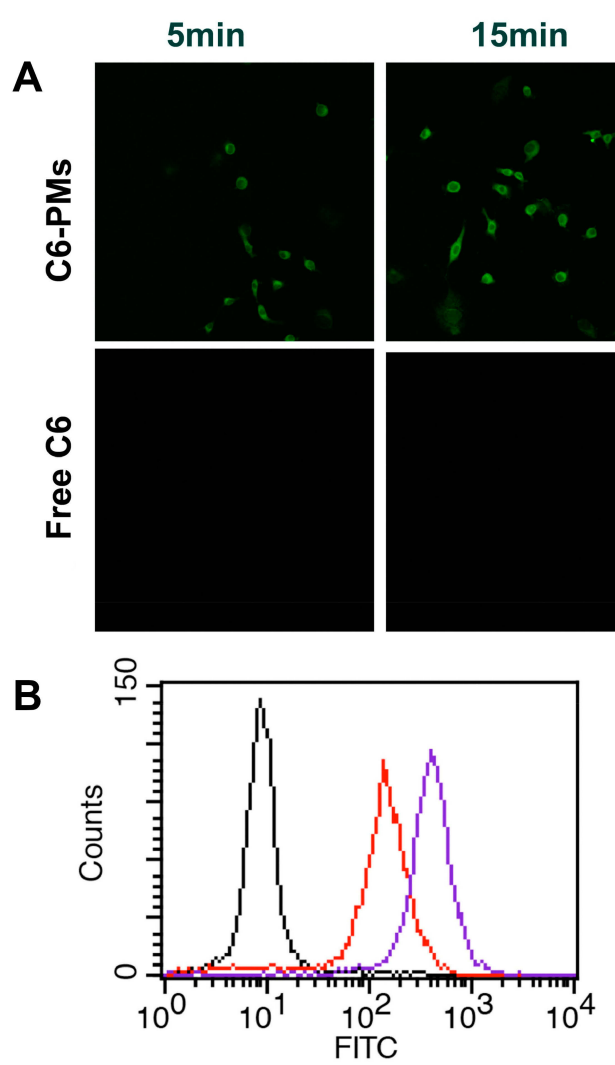

$15 \mathrm{~min}$
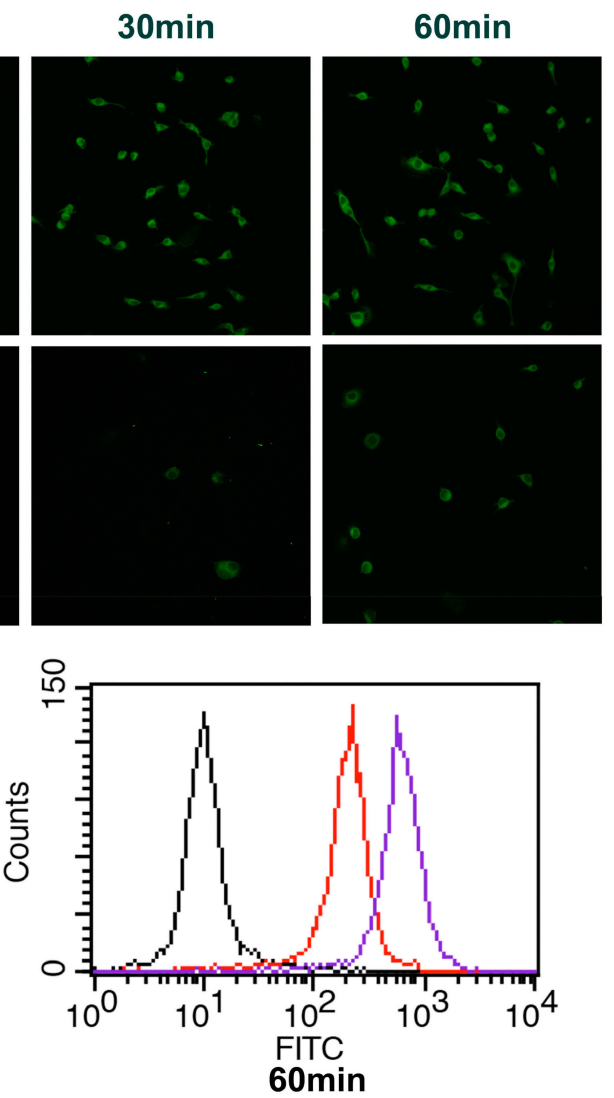

$60 \mathrm{~min}$
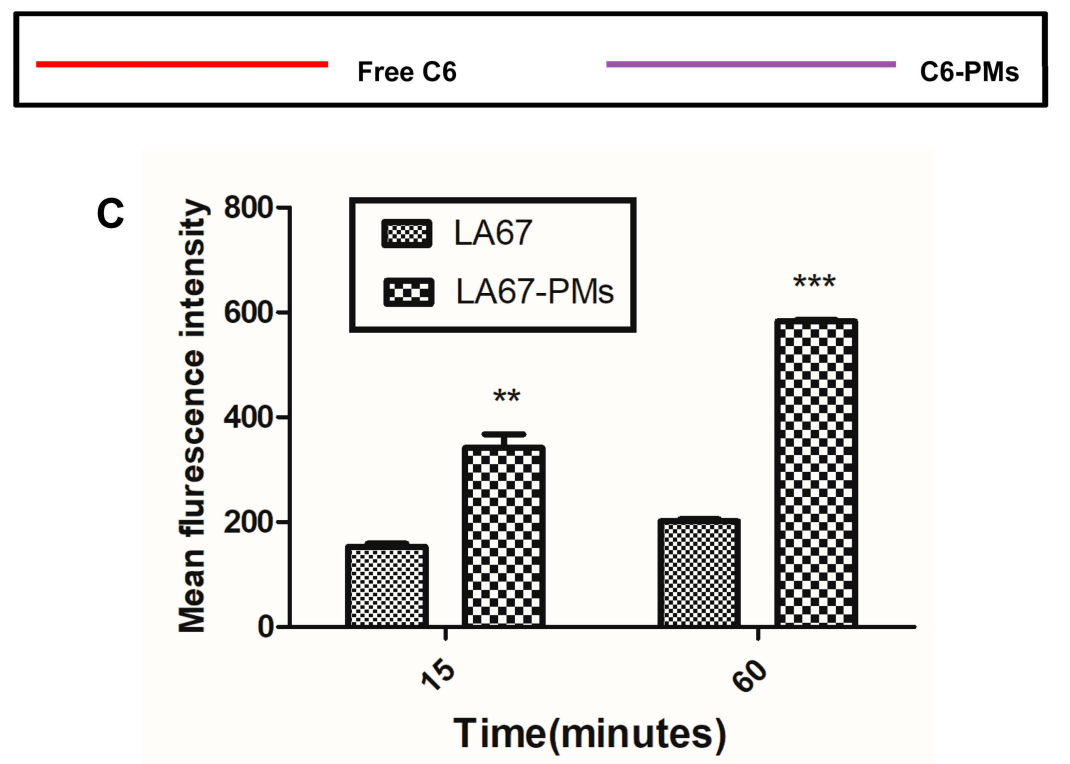

Figure 4 Cellular uptake studies of PMs.

Notes: (A) Confocal microscopic images after treatment with free C6 or C6-PMs for $5,15,30$, and 60 min. (B, C) The fluorescence intensity of cells after treatment with free $\mathrm{C} 6$ or $\mathrm{C} 6-\mathrm{PMs}$ for 15 and $60 \mathrm{~min}(\mathrm{n}=3$, mean $\pm \mathrm{SD})$; $* * P<0.01$ vs free $\mathrm{C} 6$, $* * * P<0.001$ vs free $\mathrm{C} 6$.

Abbreviations: C6, coumarin-6; PMs, polymeric micelles; C6-PMs, coumarin-6-loaded polymeric micelles; FITC, fluorescein isothiocyanate.

LA67 and LA67-PMs significantly inhibited tumor growth ( $\mathrm{P}<0.01$ vs the saline group and $\mathrm{P}<0.001$ vs the saline group, respectively). There was no significant difference between the blank PMs group and the saline group, and LA67-PMs exerted a stronger inhibitory effect than LA67 on tumor growth $(\mathrm{P}<0.01)$. At the end of the experiment, the tumor weights of mice were compared. As shown in Figure 8B, the tumor weights in the LA67 and LA67-PMs groups decreased 
A

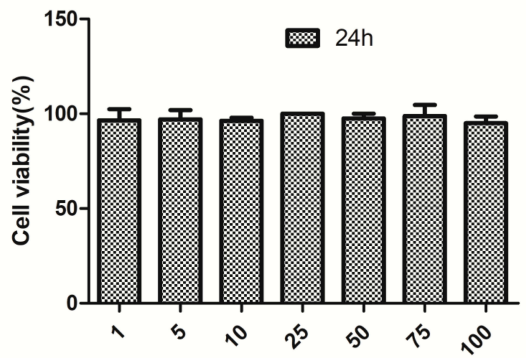

Equivalent concentration to LA67 (ng/ml)

B

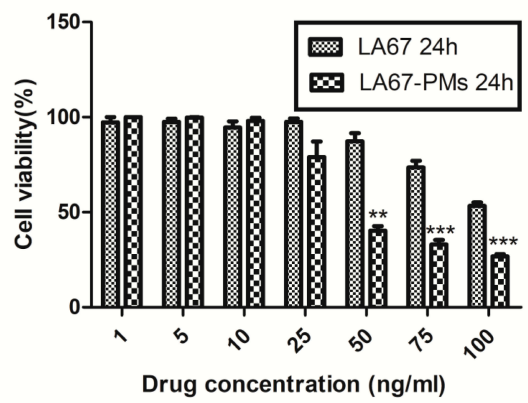

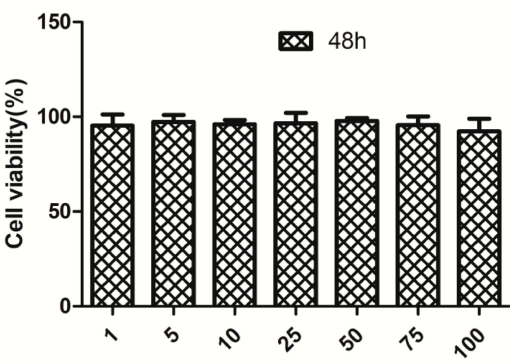

Equivalent concentration to LA67 (ng/ml)

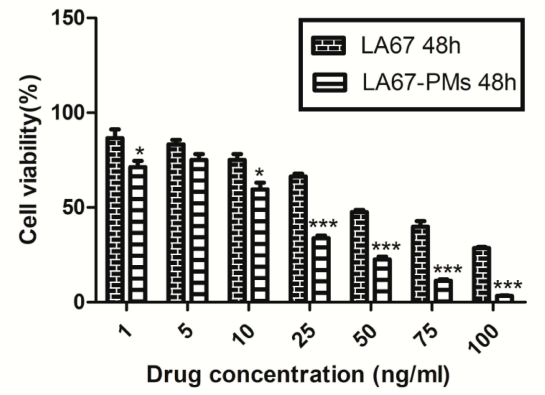

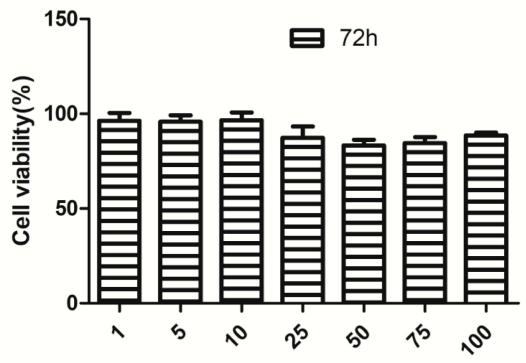

Equivalent concentration to LA67 (ng/ml)

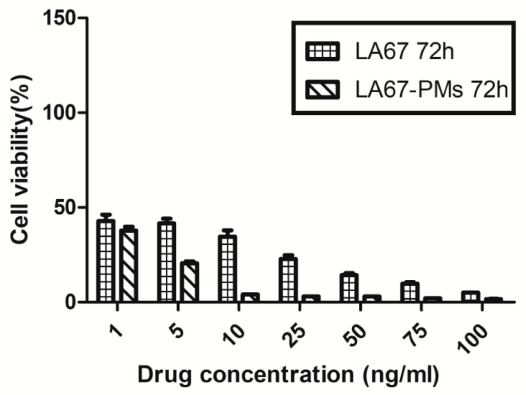

Figure 5 (A) Cytotoxicity of blank PMs to C26 cells ( $n=4$, mean \pm SD). (B) Inhibitory effect of LA67-PMs on C26 cell proliferation after 24, 48, and 72-h incubation compared with LA67 $(\mathrm{n}=4$, mean $\pm S D)$; $* P<0.05$ vs LA67, $* * P<0.0$ I vs LA67, $* * * P<0.001$ vs LA67.

Abbreviations: PMs, polymeric micelles; LA67-PMs, LA67-loaded polymeric micelles.
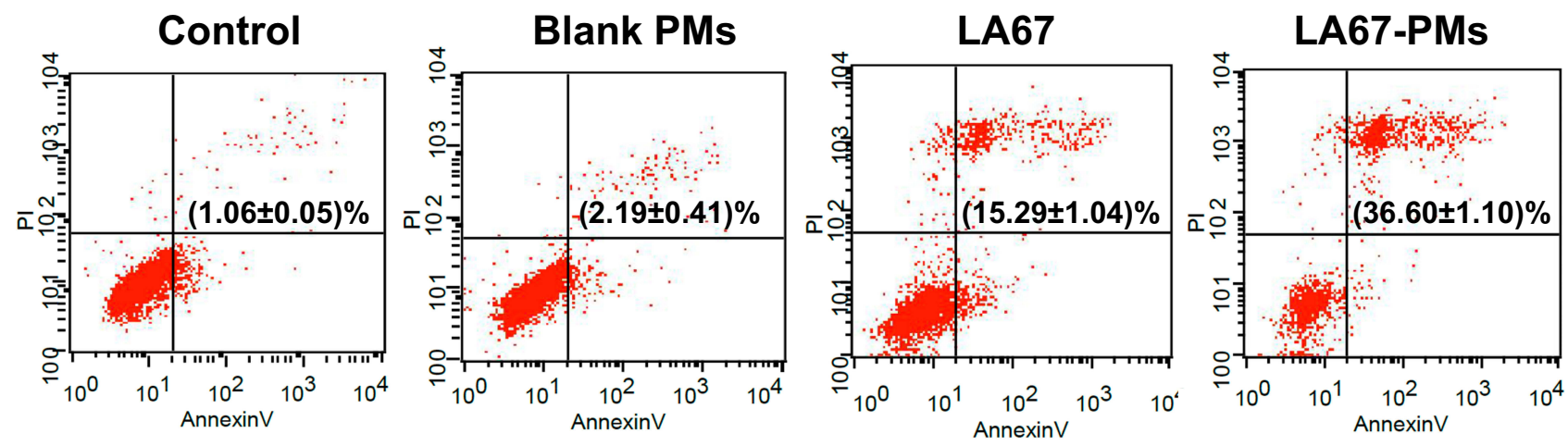

Figure 6 Influence of LA67-PMs on cell apoptosis.

Notes: The proportion of apoptotic cells in control, blank PMs, LA67 and LA67-PMs group after 48-h incubation ( $n=3$, mean \pm SD).

Abbreviations: PI, propidium iodide; PMs, polymeric micelles; LA67-PMs, LA67-loaded polymeric micelles.

significantly compared with those in the saline group $(\mathrm{P}<0.01$ and $\mathrm{P}<0.001)$. Moreover, tumor weights in the LA67-PMs group were significantly lower than those in the LA67 group $(\mathrm{P}<0.05)$. There was no significant difference between the blank PMs group and the saline group. Decreased body weight could reflect systemic drug toxicity. Body weight in the LA67 group was significantly decreased $(\mathrm{P}<0.05)$, but no significant weight loss was observed in any of the other three groups (Figure 8C). These results indicated that PMs were not toxic, and reduced the toxicity of LA67 in vivo. These observations were consistent with our in vitro cytotoxicity results. These results suggested that LA67-PMs exerted a stronger inhibitory effect on tumor growth than LA67 in vivo. LA67-PMs are not specifically colon target formulations, which usually target to specific receptors that are overexpressed in colon cancers. The selectivity to target tumors relies considerably on the EPR effect, which is considered as a passive targeting strategy. The EPR effect is recently identified as a common feature of most solid tumors and relates to the currently developed strategy of tumor-specific drug delivery using vectors. This EPR effect-driven drug delivery (more accumulation of therapeutics in tumor sites than 


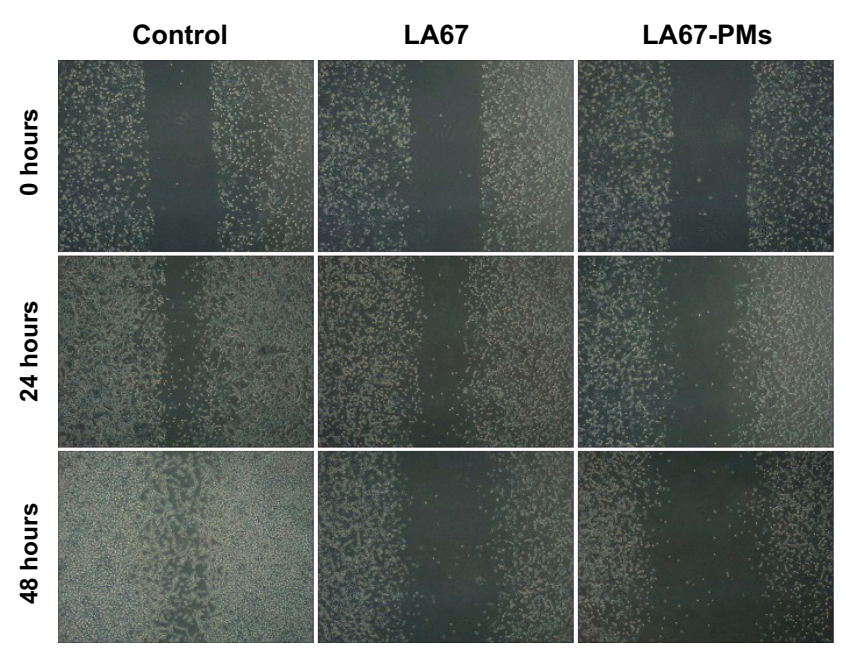

Figure 7 Influence of LA67-PMs on wound healing.

Abbreviation: LA67-PMs, LA67-loaded polymeric micelles.

other parts) consequently led to a significantly regressed tumor, without serious adverse side effects. ${ }^{51-53}$ We hypothesized that LA67-PMs improved the solubility and bioavailability of LA67, which resulted in sustained maintenance of blood drug concentrations, prolong drug circulation time, and improved accumulation of LA67 in tumors, which resulted in improved antitumor efficacy.

\section{Induction of Apoptosis, Anti-} Angiogenesis, and Anti-Proliferation of LA67-PMs in vivo

Previous studies have shown that the antitumor mechanisms of triptolide may be related to induction of apoptosis, inhibition of cell proliferation, and neovascularization, and LA67 and triptolide have similar structures. To evaluate the potential mechanisms of LA67-PMs and LA67 in inhibition of colon cancer, TUNEL assay was used to investigate apoptosis in tumor tissues. As shown in Figure 9A, tumor cell numbers were significantly decreased in response to LA67-PMs and LA67 compared with those in the saline and blank PMs groups. A lot of apoptotic cells (brown) were found in contrast, which implied that most tumor cells have been apoptotic. Moreover, there were more TUNEL-positive cells in the LA67-PMs group than in the free LA67 group, which indicated that LA67-PMs and free LA67 inhibited tumor
A

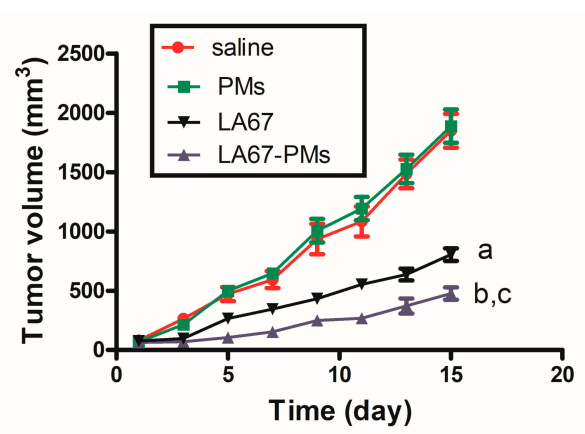

C

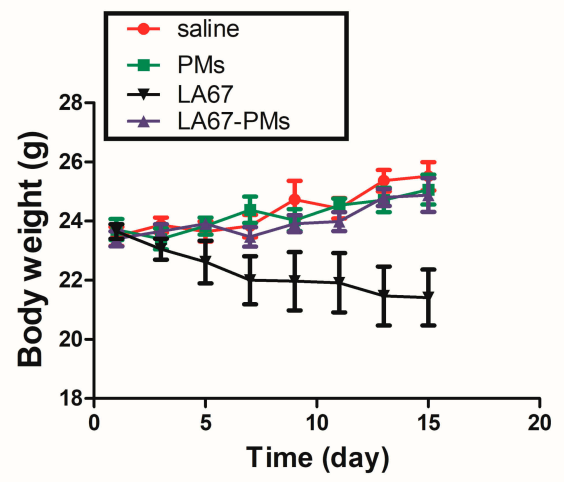

B

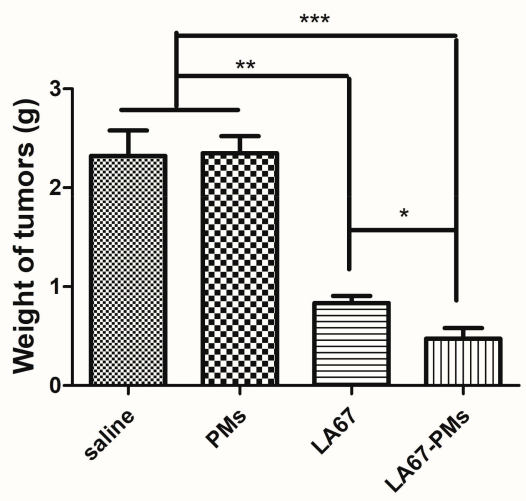

D

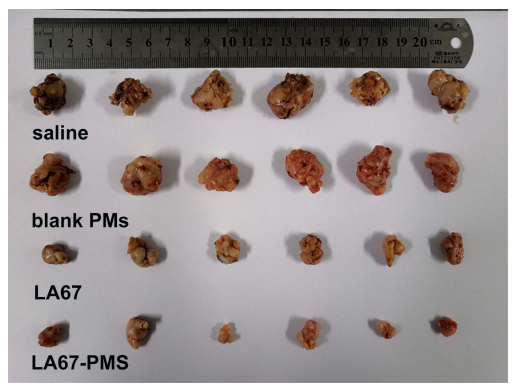

Figure 8 In vivo anti-tumor effect of LA67-PMs.

Notes: (A) Tumor volume of mice treated with saline, blank PMs, LA67 and LA67-PMs ( $n=6$, mean \pm SD). a, $P<0.001$ vs saline; b, $P<0.00$ I vs saline; c, $P<0.0$ I vs LA67. (B) Comparison of tumor weight among saline, blank PMs, LA67 and LA67-PMs group ( $n=6$, mean \pm SD). $* P<0.05$ vs LA67, $* * P<0.01$ vs saline, $* * * P<0.00$ I vs saline. (C) The body weight of mice treated with saline, blank PMs, LA67 and LA67-PMs. (D) Tumor tissues of mice treated with saline, blank PMs, LA67 and LA67-PMs.

Abbreviations: PMs, polymeric micelles; LA67-PMs, LA67-loaded polymeric micelles. 


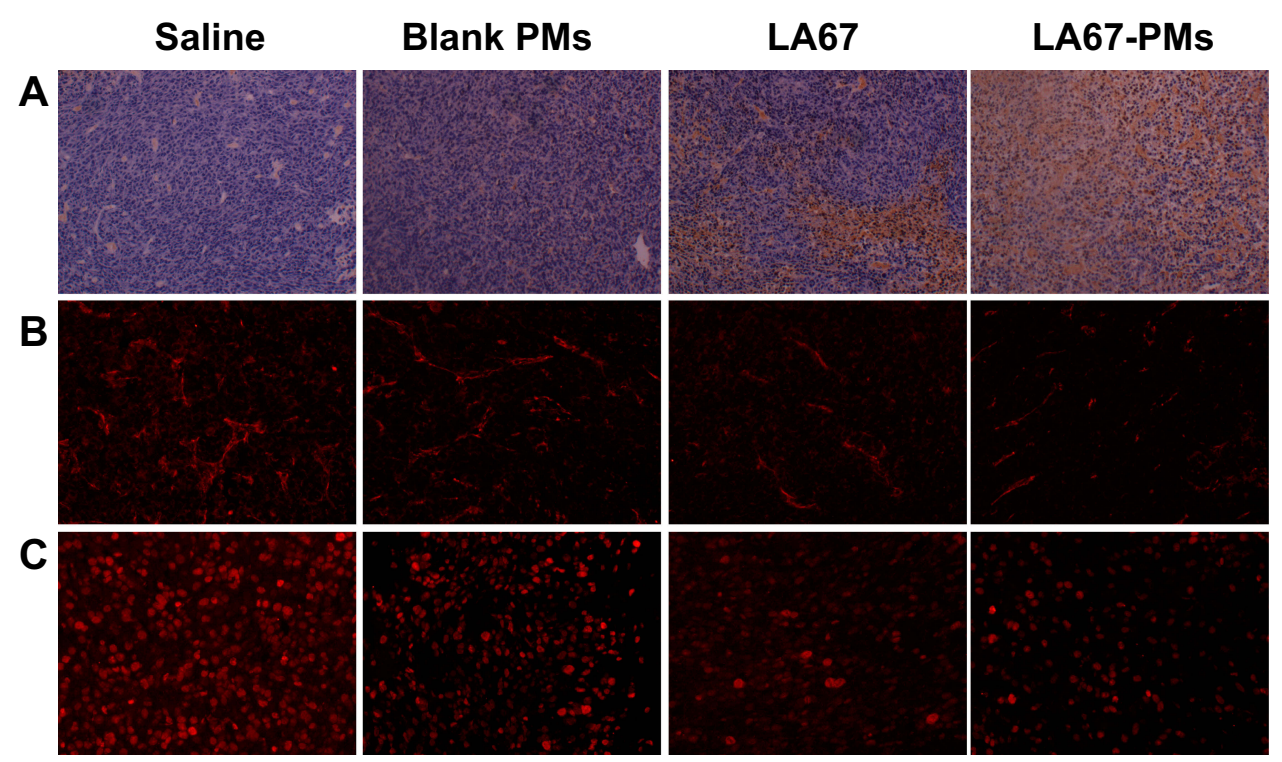

Figure 9 (A) Tumor tissue sections of saline-treated group, blank PMs treated group, free LA67 treated group, and LA67-PMs treated group were stained with TUNEL (the apoptotic cells are shown in brown). (B) Tumor tissue sections of saline-treated group, blank PMs treated group, free LA67 treated group, and LA67-PMs treated group were immunostained with CD3I (the microvessels are shown in red). (C) Tumor tissue sections of saline-treated group, blank PMs treated group, free LA67 treated group, and LA67-PMs treated group were immunostained with Ki-67 (the Ki-67 proteins are shown in red).

Abbreviations: PMs, polymeric micelles; LA67-PMs, LA67-loaded polymeric micelles; TUNEL, terminal-deoxynucleotidyl transferase-mediated nick end labeling.

growth through induction of apoptosis in vivo, and LA67PMs were more effective than free LA67.

In addition, CD31 was evaluated to investigate the anti-angiogenesis activities of LA67-PMs and LA67 in vivo. As shown in Figure 9B, microvessel density was significantly decreased in the LA67-PMs and free LA67 groups compared with that in the saline and blank PMs groups. Moreover, microvessel density was lower in the LA67-PMs than in the free LA67 group. These results suggested that LA67-PMs inhibited neovascularization more effectively than free LA67.

In addition, the Ki-67 assay was performed to investigate the anti-proliferation effects of LA67-PMs and LA67 in vivo. As shown in Figure 9C, Ki-67-positive cells decreased in response to LA67-PMs and LA67 treatment compared with those in response to saline and blank PMs.
Moreover, there were less Ki-67-positive cells in the LA67-PMs group than in the LA67 group. These results showed that LA67-PMs and free LA67 inhibited tumor growth through inhibition of cell proliferation in vivo, and LA67-PMs were more effective than free LA67.

\section{Inhibition of Metastasis by LA67-PMs}

The liver is the most common distant metastasis site of CRC, and liver metastasis is the main cause of death in patients with CRC. Approximately $40-50 \%$ of patients with CRC have organ metastasis, about $15-25 \%$ of patients with CRC have liver metastasis at the time of diagnosis, and $15-25 \%$ of patients with CRC have liver metastasis following surgical treatment of CRC. Colorectal cancer liver metastases (CRLM) seriously affect prognosis, only $15-20 \%$ of patients with CRLM patients are candidates for surgical resection,

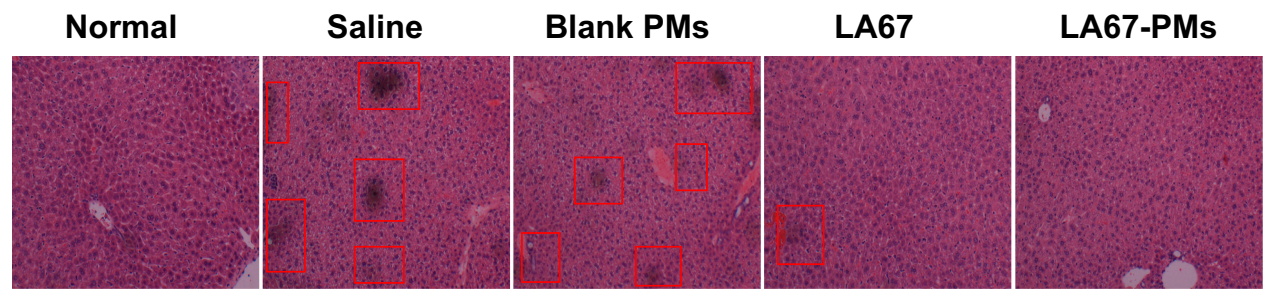

Figure 10 Anti-metastatic activity of LA67-PMs.

Notes: livers of normal and tumor-bearing mice after H\&E staining (magnification: 100). Red boxes show the tumor metastasis loci in the livers.

Abbreviations: PMs, polymeric micelles; LA67-PMs, LA67-loaded polymeric micelles; H\&E, hematoxylin and eosin. 
and the 5-year survival rate in these patients is only $20-40 \%{ }^{54-56}$ To investigate the inhibitory effect of LA67PMs on distant organ metastasis, the livers of all mice were harvested and stained with H\&E. Figure 10 shows that there were obvious liver metastases (red box) in the saline and blank PMs groups, and a small metastatic region was observed in the free LA67 group. However, no obvious abnormalities were observed in liver tissues in the LA67PMs group. These results suggested that LA67-PMs effectively inhibited CRLM to a greater extent than free LA67.

\section{Survival Analysis}

This study showed that LA67-PMs inhibited tumor growth and distant organ metastasis. We further investigated the impact of LA67-PMs on survival time. Figure 11 shows that the survival time in the saline group was 37 days and the survival time in the blank PMs group was 38 days. The survival times in the LA67 (48 days) and LA67-PMs (53 days) groups were significantly longer than those in the saline and blank PMs groups $(\mathrm{P}<0.01$ vs saline group and $\mathrm{P}<0.001$ vs saline group). Moreover, these results also implied that LA67-PMs prolonged survival time of mice more effectively than free LA67 $(\mathrm{P}<0.05)$.

\section{Conclusion}

In this study, we successfully developed LA67-PMs. These polymeric micelles exhibited increased solubility, small particle size, high drug entrapment efficiency, good stability, and slow, sustained release. Moreover, we evaluated the antitumor activities of LA67-PMs in vitro and in

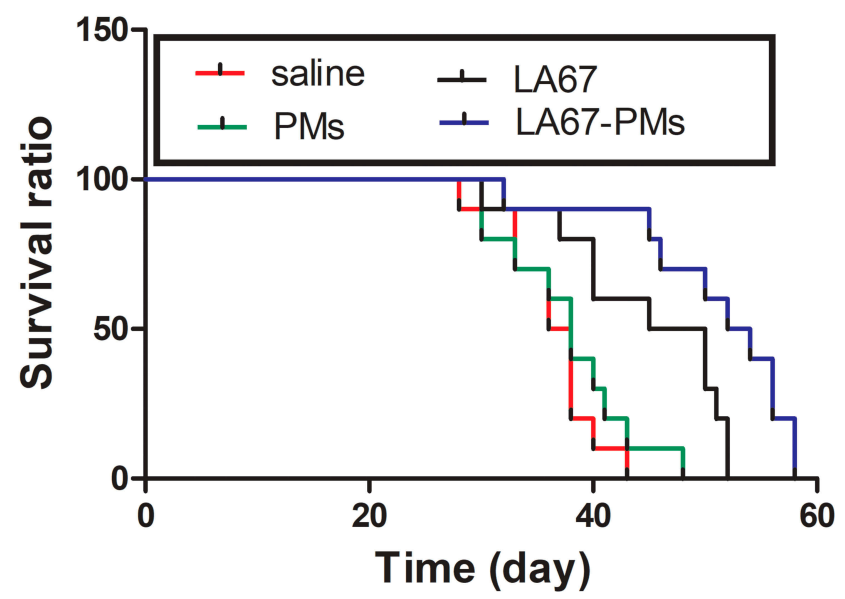

Figure I I Survival curves of C26 tumor-bearing mice. $(n=10)$.

Notes: $\mathrm{P}<0.0$ I, LA67 vs saline; $\mathrm{P}<0.00$ I, LA67-PMs vs saline; $P<0.05$, LA67-PMs vs LA67.

Abbreviations: PMs, polymeric micelles; LA67-PMs, LA67-loaded polymeric micelles. vivo. These results indicated that LA67-PMs were more efficiently internalized, more effectively induced apoptosis, and more effectively repressed proliferation and migration of C26 cancer cells than free LA67 in vitro. Furthermore, LA67-PMs significantly inhibited growth and metastasis of tumors in vivo, which resulted in prolonged survival time in mice. The enhanced therapeutic efficacy of LA67-PMs might have been due to increased solubility and bioavailability, slow, sustained drug release, and improved drug delivery to cancer cells. In conclusion, our study showed that LA67-PMs may be a promising formulation for treatment of colon cancer, and provide a novel strategy for clinical practice. Future studies will further investigate the pharmacokinetics and antitumor mechanisms of LA67-PMs, which may allow for translation of use of this formulation to clinical practice.

\section{Acknowledgments}

This research was financially supported by the Fundamental Research Funds for the Central Universities (No.3332018089), the Drug Innovation Major Project (2018ZX09711001-002-005), and the CAMS Innovation Fund for Medical Sciences (2017-I2M-1-011).

\section{Disclosure}

Dr Minhu Cui reports a patent 201911100203.7 pending. The authors declare no other conflicts of interest in relation to this paper.

\section{References}

1. Inés M, Cristina S-D-D, Alberto PD, Elena C, María RY. Colorectal carcinoma: a general overview and future perspectives in colorectal cancer. Int J Mol Sci. 2017;18(1):197. doi:10.3390/ijms 18010197

2. Fitzmaurice C, Allen C, Barber RM, et al. Global, regional, and national cancer incidence, mortality, years of life lost, years lived with disability, and disability-adjusted life-years for 32 cancer groups, 1990 to 2015. JAMA Oncol. 2017;3(4):524. doi:10.1001/ jamaoncol.2016.5688

3. Lin CC, Calvo E, Papadopoulos KP, et al. Phase I study of cetuximab, erlotinib, and bevacizumab in patients with advanced solid tumors. Cancer Chemother Pharmacol. 2009;63(6):1065-1071. doi:10.1007/ s00280-008-0811-x

4. Chung HH, Jang BI. A perspective: role of targeted therapy in colon cancer. Korean J Gastroenterol. 2013;61(3):128-135. doi:10.4166/ kjg.2013.61.3.128

5. Huang K-Y, Kao S-H, Wang W-L, et al. Small molecule T315 promotes casitas B-lineage lymphoma-dependent degradation of epidermal growth factor receptor via Y1045 autophosphorylation. Am J Respir Crit Care Med. 2016;193(7):753. doi:10.1164/rccm.20150202500C

6. Abdul Razak AR, Mau-Soerensen M, Gabrail NY, et al. First-in-class, first-in-human phase I study of selinexor, a selective inhibitor of nuclear export, in patients with advanced solid tumors. J Clin Oncol. 2016;34(34):JCO.2015.2065.3949. doi:10.1200/JCO.2015.65.3949 
7. Beretta GL, Mantegazza F, Misiak M. Methods for elucidation of DNA-anticancer drug interactions and their applications in the development of new drugs. Curr Pharm Des. 2016;22(44):6596-611.

8. Chen BJ. Triptolide, a novel immunosuppressive and anti-inflammatory agent purified from a Chinese herb Tripterygium wilfordii Hook F. Leuk Lymphoma. 2001;42(3):253-265. doi:10.3109/10428190109064582

9. Shi X, Jin Y, Cheng C, et al. Triptolide inhibits Bcr-Abl transcription and induces apoptosis in STI571-resistant chronic myelogenous leukemia cells harboring T315I mutation. Clin Cancer Res. 2009;15 (5):1686. doi:10.1158/1078-0432.CCR-08-2141

10. Chan E, Cheng S, Sin F, Xie Y. Triptolide induced cytotoxic effects on human promyelocytic leukemia, T cell lymphoma and human hepatocellular carcinoma cell lines. Toxicol Lett. 2001;122(1):8187. doi:10.1016/S0378-4274(01)00353-8

11. Fidler JM, Li K, Chung C, Wei K, Rosen GD. PG490-88, a derivative of triptolide, causes tumor regression and sensitizes tumors to chemotherapy. Mol Cancer Ther. 2003;2(9):855-862.

12. Frese S, Pirnia F, Miescher D, et al. PG490-mediated sensitization of lung cancer cells to Apo2L/TRAIL-induced apoptosis requires activation of ERK2. Oncogene. 2003;22(35):5427-5435. doi:10.1038/sj. onc. 1206842

13. Kiviharju TM, Lecane PS, Sellers RG, Peehl DM. Antiproliferative and proapoptotic activities of triptolide (PG490), a natural product entering clinical trials, on primary cultures of human prostatic epithelial cells. Clin Cancer Res. 2002;8(8):2666-2674.

14. Tengchaisri T, Chawengkirttikul R, Rachaphaew N, Reutrakul V, Sangsuwan R, Sirisinha S. Antitumor activity of triptolide against cholangiocarcinoma growth in vitro and in hamsters. Cancer Lett. 1998;133(2):169-175. doi:10.1016/S0304-3835(98)00222-5

15. Wei YS, Adachi I. Inhibitory effect of triptolide on colony formation of breast and stomach cancer cell lines. Zhongguo Yao li Xue Bao. 1991;12(5):406.

16. Yang S, Chen J, Guo Z, et al. Triptolide inhibits the growth and metastasis of solid tumors. Mol Cancer Ther. 2003;2(12):65.

17. Zhou GX, Ding XL, Huang JF, et al. Apoptosis of human pancreatic cancer cells induced by triptolide. World J Gastroenterol. 2008;14 (10):1504-1509. doi:10.3748/wjg.14.1504

18. Shamon LA, Pezzuto JM, Graves JM, et al. Evaluation of the mutagenic, cytotoxic, and antitumor potential of triptolide, a highly oxygenated diterpene isolated from Tripterygium wilfordii. Cancer Lett 1997;112(1):113-117. doi:10.1016/S0304-3835(96)04554-5

19. Li Z, Zhou Z-L, Miao Z-H, et al. Design and synthesis of novel C14hydroxyl substituted triptolide derivatives as potential selective antitumor agents. J Med Chem. 2009;52(16):5115-5123. doi:10.1021/ jm900342g

20. Liu Q. Triptolide and its expanding multiple pharmacological functions. Int Immunopharmacol. 2011;11(3):377-383. doi:10.1016/j. intimp.2011.01.012

21. $\mathrm{Xu} \mathrm{H}$, Tang H, Feng H, Li Y. Design, synthesis and anticancer activity evaluation of novel $\mathrm{C} 14$ heterocycle substituted epi-triptolide. Eur J Med Chem. 2014;73:46-55. doi:10.1016/j ejmech.2013.11.044

22. Yu DQ, Zhang DM, Wang HB, Liang XT. Structure modification of triptolide, a diterpenoid from Tripterygium wilfordii. Acta Pharmaceutica Sinica. 1992;27(11):830-836.

23. Zhang D, Zang Y, Chen X, et al. Triptolide derivatives, their preparation and use. China. 2018;5-16.

24. Mirrahimi M, Khateri M, Beik J, et al. Enhancement of chemoradiation by co-incorporation of gold nanoparticles and cisplatin into alginate hydrogel. J Biomed Mater Res B Appl Biomater. 2019;107 (8):2658-2663. doi:10.1002/jbm.b.34356

25. Montazerabadi A, Beik J, Irajirad R, et al. Folate-modified and curcumin-loaded dendritic magnetite nanocarriers for the targeted thermochemotherapy of cancer cells. Artif Cells Nanomed Biotechnol. 2019;47 (1):330-340. doi:10.1080/21691401.2018.1557670
26. Beik J, Khateri M, Khosravi Z, et al. Gold nanoparticles in combinatorial cancer therapy strategies. Coord Chem Rev. 2019;387:299324. doi:10.1016/j.ccr.2019.02.025

27. Wang Y, Liu T, Li H. Enhancement of triptolide-loaded micelles on tumorigenicity inhibition of human ovarian cancer. J Biomater Sci Polymer Ed. 2016;27(7):545-556. doi:10.1080/09205063.2015. 1131667

28. Xu L, Chen H, Xu H, Yang X. Anti-tumour and immuno-modulation effects of triptolide-loaded polymeric micelles. Eur J Pharm Biopharm. 2008;70(3):741-748.

29. Zhou Z, Tang J, Sun Q, Murdoch WJ, Shen Y. A multifunctional PEG-PLL drug conjugate forming redox-responsive nanoparticles for intracellular drug delivery. J Mater Chem B. 2015;3(38):7594-7603. doi:10.1039/C5TB01027F

30. Gao Y-E, Ma X, Hou M, et al. Highly cell-penetrating and ultra-pHresponsive nanoplatform for controlled drug release and enhanced tumor therapy. Colloids Surf B Biointerfaces. 2017;159:484. doi:10.1016/j.colsurfb.2017.08.018

31. Lehner R, Wang X, Marsch S, Hunziker P. Intelligent nanomaterials for medicine: carrier platforms and targeting strategies in the context of clinical application. Nanomed Nanotechnol Biol Med. 2013;9 (6):742-757. doi:10.1016/j.nano.2013.01.012

32. Tomii Y. Lipid formulation as a drug carrier for drug delivery. Curr Pharm Des. 2002;8(6):467-474. doi:10.2174/1381612023395871

33. Wang B, Friess W. Spray drying of silica microparticles for sustained release application with a new sol-gel precursor. Int J Pharm. 2017;532(1):281. doi:10.1016/j.ijpharm.2017.09.016

34. Niaz T, Hafeez Z, Imran M. Prospectives of antihypertensive nanoceuticals as alternative therapeutics. Curr Drug Targets. 2016;17 (11):1269-1280.

35. Kim TY, Kim DW, Chung JY, et al. Phase I and pharmacokinetic study of Genexol-PM, a Cremophor-free, polymeric micelle-formulated paclitaxel, in patients with advanced malignancies. Clin Cancer Res. 2004;10(11):3708-3716.

36. Lee KS, Chung HC, Im SA, et al. Multicenter phase II trial of Genexol-PM, a Cremophor-free, polymeric micelle formulation of paclitaxel, in patients with metastatic breast cancer. Breast Cancer Res Treat. 2008;108(2):241-250. doi:10.1007/s10549-007-9591-y

37. Yang XL, Yang YJ, Xu HB, et al. Research progress of triptolideloaded nanoparticles delivery systems. Mater Sci Eng C Mater Biol Appl. 2005;5(2):138-142.

38. Zheng Q, Gong T, Sun X, Zhang Z-R. Synthesis, characterization and in vitro evaluation of triptolide-lysozyme conjugate for renal targeting delivery of triptolide. Arch Pharm Res. 2006;29(12):1164-1170. doi:10.1007/BF02969309

39. Li Y, Yang F, Chen W, et al. A novel monomethoxy polyethylene glycol$\left.\right|^{\wedge} \# 8211$; polylactic acid polymeric micelles with higher loading capacity for docetaxel and well-reconstitution characteristics and its anti-metastasis study. Chem Pharm Bull (Tokyo). 2012;60 (9):1146-1154. doi:10.1248/cpb.c12-00323

40. Chen L, Huang W, Gao Z, Fang W, Jin M. Lx2-32c-loaded polymeric micelles with small size for intravenous drug delivery and their inhibitory effect on tumor growth and metastasis in clinically associated 4T1 murine breast cancer. Int J Nanomedicine. 2016;11:54575742. doi:10.2147/IJN.S116347

41. Moughton AO, Hillmyer MA, Lodge TP. Multicompartment block polymer micelles. Macromolecules. 2012;45(1):2-19. doi:10.1021/ ma201865s

42. Valenzuelaoses JK, García MC, Feitosa VA, et al. Development and characterization of miltefosine-loaded polymeric micelles for cancer treatment. Mater Sci Eng C. 2017;81:327. doi:10.1016/j. msec.2017.07.040

43. Zhang Y, Ren T, Gou J, et al. Strategies for improving the payload of small molecular drugs in polymeric micelles. J Control Release. 2017;261:S0168365917300548. doi:10.1016/j.jconrel.2017.01.047 
44. Zhulina EB, Borisov OV. Theory of block polymer micelles: recent advances and current challenges. Macromolecules. 2012;45 (11):4429-4440. doi:10.1021/ma300195n

45. Bae Y, Alani AWG, Rockich NC, Lai TSZC, Kwon GS. Mixed pHsensitive polymeric micelles for combination drug delivery. Pharm Res. 2010;27(11):2421-2432. doi:10.1007/s11095-010-0234-3

46. Wang J, Xu W, Li S, et al. Polylactide-cholesterol stereocomplex micelle encapsulating chemotherapeutic agent for improved antitumor efficacy and safety. J Biomed Nanotechnol. 2018;14(12):21022113. doi:10.1166/jbn.2018.2624

47. Wang $\mathrm{H}$, Zhao P, Su W, et al. PLGA/polymeric liposome for targeted drug and gene co-delivery. Biomaterials. 2010;31(33):8741-8748. doi:10.1016/j.biomaterials.2010.07.082

48. Simonoska Crcarevska M, Geskovski N, Calis S, et al. Definition of formulation design space, in vitro bioactivity and in vivo biodistribution for hydrophilic drug loaded PLGA/PEO-PPO-PEO nanoparticles using OFAT experiments. Eur J Pharm Sci. 2013;49(1):65-80. doi:10.1016/j.ejps.2013.02.004

49. Meng L, Chu X, Xing H, et al. Improving glioblastoma therapeutic outcomes via doxorubicin-loaded nanomicelles modified with borneol. Int J Pharm. 2019;567:118485. doi:10.1016/j.ijpharm.2019.118485

50. Venkatesan P, Puvvada N, Dash R, et al. The potential of celecoxibloaded hydroxyapatite-chitosan nanocomposite for the treatment of colon cancer. Biomaterials. 2011;32(15):3794-3806. doi:10.1016/j. biomaterials.2011.01.027
51. Greish K. Enhanced permeability and retention (EPR) effect for anticancer nanomedicine drug targeting. Methods Mol Biol. 2010;624:25-37.

52. Maeda H. Polymer therapeutics and the EPR effect. J Drug Target. 2017;25(9-10):781-785. doi:10.1080/1061186X.2017.1365878

53. Fang J, Nakamura H, Maeda $H$. The EPR effect: unique features of tumor blood vessels for drug delivery, factors involved, and limitations and augmentation of the effect. Adv Drug Deliv Rev. 2011;63 (3):136-151. doi:10.1016/j.addr.2010.04.009

54. Jeong W-J. Strategies to overcome resistance to epidermal growth factor receptor monoclonal antibody therapy in metastatic colorectal cancer. World J Gastroenterol. 2014;20(29):9862. doi:10.3748/wjg. v20.i29.9862

55. Qin X, Xu J, Ren L, et al. Analysis of chinese guidelines for diagnosis and comprehensive treatment of liver metastasis from colorectal cancer (V 2016). J Clin Surg. 2017;25(1):15-20.

56. Zheng S, Zhang S, Huang Y. Retrospect and current status of research on colorectal cancer in the past 30 years. J Pract Oncol. 2016;31 (1):2-5.
International Journal of Nanomedicine

\section{Publish your work in this journal}

The International Journal of Nanomedicine is an international, peerreviewed journal focusing on the application of nanotechnology in diagnostics, therapeutics, and drug delivery systems throughout the biomedical field. This journal is indexed on PubMed Central, MedLine, CAS, SciSearch ${ }^{\mathbb{B}}$, Current Contents ${ }^{\mathbb{R}} /$ Clinical Medicine,

\section{Dovepress}

Journal Citation Reports/Science Edition, EMBase, Scopus and the Elsevier Bibliographic databases. The manuscript management system is completely online and includes a very quick and fair peer-review system, which is all easy to use. Visit http://www.dovepress.com/ testimonials.php to read real quotes from published authors. 